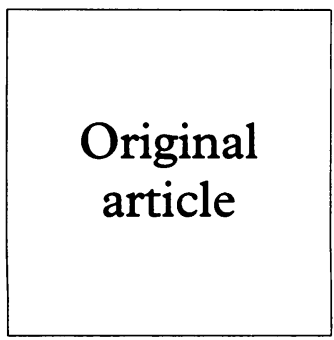

\title{
Development of intralesional therapy with fluorouracil/adrenaline injectable gel for management of condylomata acuminata: two phase II clinical studies
}

\author{
J M Swinehart, R B Skinner, J M McCarty, B H Miller, S K Tyring, A Korey, \\ E K Orenberg ${ }^{\star}$
}

Objectives: To evaluate a sustained release chemotherapy for treating condylomata acuminata with an injectable gel containing fluorouracil and adrenaline (5-FU/adrenaline gel). Study $1-$ To assess contributions of the components of 5-FU/adrenaline gel to efficacy. Study 2-To assess therapeutic contribution of adrenaline and safety and efficacy of the formulations.

Design: Randomised, double blind, placebo controlled studies.

Setting: Private practices and university clinics in the United States.

Patients: Men and women with new, recurrent, or refractory external condylomata acuminata. Intervention: Six injections over 8 weeks; follow up visits at weeks $1,4,8$, and 12 .

Main outcome measures: Efficacy: patient/wart response, times to complete response, recurrence rates. Safety: injection reactions, tissue conditions, other adverse events, laboratory studies. Results: Study 1: 132 evaluable patients. Complete response (CR) rate was highest for the 5-FU/adrenaline gel group, followed by the 5-FU/adrenaline solution group, then the 5-FU gel group. 5-FU, adrenaline, and the collagen gel vehicle (in the presence of 5-FU) significantly affected CR and strongly influenced time to CR. The effects of 5-FU and adrenaline were statistically significant. Cutaneous reactions were mild to moderate. Study 2: 187 evaluable patients. Patients treated with 5-FU/adrenaline gel had a significantly higher CR rate and lower cumulative 90 day recurrence rate than those treated with 5-FU gel without adrenaline. Treatments were generally well tolerated, with only three treatment related, serious adverse events.

Conclusion: 5-FU/adrenaline gel is safe and efficacious for treatment of condylomata acuminata, and when compared with individual or various combinations of components, this formulation provided the greatest therapeutic advantage.

(Genitourin Med 1997;73:481-487)

Research Center,

Denver, Colorado,

USA

J M Swinehart

Department of

Dermatology,

University of

Tennessee, Memphis,

Tennessee, USA

R B Skinner

Fresno, California,

USA

J M McCarty

Dermatology

Associates, Portland,

Oregon, USA

B H Miller

Department of

Dermatology,

University of Texas

Medical Branch,

Galveston, Texas, USA

S K Tyring

Matrix

Pharmaceutical, Inc, Fremont, California,

USA

A Korey

E K Orenberg

*A complete list of

participants in addition

to the authors appears at the end of the paper.

Correspondence to:

Dr J M Swinehart, Colorado Medical Research Center, Harvard Park Medical Plaza 950 E Harvard Avenue Suite 630, Denver, CO 80210, USA.

Accepted for publication

11 June 1997

Keywords: condylomata acuminata; genital warts; STDs; fluorouracil; adrenaline

\section{Introduction}

Condylomata acuminata, highly contagious warts in the genital and perianal region, are difficult to treat, have high recurrence rates, and are increasing in incidence. ${ }^{1}$ The disease remains a therapeutic challenge because current ablative and topical treatments yield low response rates and may lead to adverse events. The causative agent, human papillomavirus (HPV) infection, is usually not eradicated by treatment. While genital condylomata are generally benign growths, patients are concerned about the cosmetic appearance of warts, psychosocial issues of having a sexually transmitted disease, the risk of transmission to a sexual partner, and fears about the association of HPV infection with cervical cancer. ${ }^{2}$ There is no known cure for condylomata acuminata, and treatment goals are limited to reducing the visible manifestations of the warts, thereby leaving the patient susceptible to possible self reinfection by latent infection as well as serving as an unitting transmitter of infection to sexual partners. ${ }^{3}$
These are strong motivation factors to seek improved therapies for condylomata acuminata. We investigated a new method of delivering chemotherapy (fluorouracil (5-FU)) directly to genital HPV warts as an alternative to the typical chemotherapeutic modality of applying topical 5-FU cream, ${ }^{4-8}$ which has limited cutaneous absorption. This novel delivery system combines 5-FU and adrenaline in an aqueous gel system (5-FU/adrenaline gel), using purified bovine collagen as a biodegradable carrier matrix and gellant. Because this system provides sustained drug availability, the diseased tissue is exposed to high drug concentrations for extended periods. ${ }^{9}$ Intralesional therapy with 5-FU/adrenaline gel provides an improved therapeutic index, is under evaluation for treatment of basal cell carcinoma ${ }^{1011}$ and squamous cell carcinoma of the skin, ${ }^{12} 13$ and has been explored for treatment of limited plaque psoriasis. ${ }^{14}$

This paper describes two phase II studies. Study 1, a randomised, double blind, controlled trial with 132 patients, had eight treat- 
ment groups consisting of the components or various combinations of components of the 5-FU/adrenaline gel formulation and was designed principally to assess the component contribution to therapy. Study 2 was a randomised, double blind, placebo controlled trial with 187 patients and three treatment groups consisting of 5-FU/adrenaline gel, 5-FU gel, and placebo gel. It focused in greater depth on the therapeutic contribution of adrenaline to therapy and investigated the safety and efficacy of the formulations used for the three treatment groups. Response rates, times to complete response, and recurrence rates were evaluated for each treatment formulation.

\section{Methods}

\section{PATIENTS}

Patients included those who had new, recurrent, or refractory external condylomata for at least 3 months (study 1 ) or 1 month (study 2) before the screening visit. No patients who had received treatment to target sites within 2 weeks of enrolment were admitted to the study. Also excluded were patients with large plaques of warts (study 2) or total wart areas that required more than 3 or $5 \mathrm{ml}$ of 5 -FU/adrenaline gel in studies 1 or 2 , respectively, and patients with a known sensitivity to any of the study drugs or components. Patients received no other condyloma treatment during the trial, but ablative treatment of internal warts was allowed. They were required to be in good general health, with negative human immunodeficiency virus status. All patients agreed to use specified methods of birth control during the study. Women with high grade cervical dysplasia and those who were pregnant or lactating were excluded.

Before the first treatment, patients signed an informed consent approved by the ethics review board of each study centre. The initial screening visit involved a complete physical examination, medical history, a complete skin examination to assess condylomata, and baseline laboratory tests (complete blood count, serum chemistry, urinalysis, HIV antibody titre, and serum pregnancy test for women).

\section{INVESTIGATIONAL AGENTS}

The investigational agent, fluorouracil (5-FU)/ adrenaline (epinephrine) injectable gel (AccuSite Injectable Gel, Matrix Pharmaceutical, Inc, Fremont, CA, USA) is a viscous, aqueous gel composed of the chemotherapeutic drug fluorouracil $(30 \mathrm{mg} / \mathrm{ml})$, the vasoconstrictor adrenaline $(0.1 \mathrm{mg} / \mathrm{ml})$, purified bovine collagen as a carrier matrix, and other inactive excipients, such as buffering and osmotic agents. The constituents were mixed by syringe to syringe transfer just before use. Study materials were prepared, mixed, and administered identically for all treatment groups. In study 1 , a saline solution was substituted for the component(s) not included in the formulation used in a particular treatment group, and in study 2, saline was substituted for the active drug in the placebo formulation.

\section{STUDY DESIGN}

The studies were performed in 14 study sites by clinicians specialising in dermatology, gynaecology, infectious disease, and urology in clinics based in teaching hospitals and private practices in the United States. Studies were conducted under good clinical practice procedures. All study sites received training for drug preparation, injection technique, wart measurements, and use of case report forms in order to ensure standardised experimental procedures. Study 1 was a randomised, double blind, controlled trial designed to evaluate the contribution of each component and consisted of eight treatment groups. According to a randomisation schedule, patients were assigned to receive 5-FU/adrenaline gel, 5-FU gel (without adrenaline), adrenaline gel (without 5-FU), gel vehicle alone (placebo gel), 5-FU/adrenaline solution, 5-FU solution, adrenaline solution, or saline solution. Study 2 was a randomised, double blind, placebo controlled study with three treatment groups. Patients were randomised to receive 5-FU/ adrenaline gel, 5-FU gel, or placebo gel. Because the appearances of the test formulations in study 1 were visibly different, one investigator prepared and administered the test agent, and another evaluated clinical response and documented safety and efficacy. This separation of roles was not necessary for study 2 , in which the formulations were not visibly different.

In both studies, all condylomata present at baseline were treated. The dose per wart was determined at baseline in accordance with a predetermined dosing schedule based on wart area. In study 1 , the minimum dose of test agent for warts up to $30 \mathrm{~mm}^{2}$ was $0.2 \mathrm{ml}(6$ $\mathrm{mg}$ of $5-\mathrm{FU}, 0.02 \mathrm{mg}$ of adrenaline), and the maximum weekly dose was $3 \mathrm{ml}$ ( $90 \mathrm{mg}$ of 5-FU, $0.3 \mathrm{mg}$ of adrenaline), with a maximum cumulative dose for $5-\mathrm{FU}$ of $540 \mathrm{mg}$. In study 2 , the minimum dose of test agent for warts up to $30 \mathrm{~mm}^{2}$ was $0.25 \mathrm{ml}(7.5 \mathrm{mg}$ of $5-\mathrm{FU}$, $0.025 \mathrm{mg}$ of adrenaline), and the maximum weekly dose of test agent was $5 \mathrm{ml}(150 \mathrm{mg}$ of 5-FU, $0.5 \mathrm{mg}$ of adrenaline), with a maximum cumulative dose for 5-FU of $900 \mathrm{mg}$ for up to a maximum of six treatments. For analysis, patients in study 2 were stratified into three groups based on total baseline wart area: $\leqslant 55 \mathrm{~mm}^{2}, 56-100 \mathrm{~mm}^{2}$, and $>100 \mathrm{~mm}^{2}$.

Patients received up to six treatments to be completed by week 8 . At the week 1 follow up visit, the baseline laboratory tests were repeated. Follow up visits took place at $1,4,8$, and 12 weeks after the last treatment or until recurrence of disease $(>50 \%$ increase in wart area or wart count from baseline), whichever occurred first.

The physician injected the investigational agent intradermally directly under the condyloma and surrounding $5 \mathrm{~mm}$ of tissue using a Luer-Lok syringe fitted with a 30 gauge needle. The needle was inserted approximately $5 \mathrm{~mm}$ from the base of the wart at about a 45 degree angle, and the agent was slowly injected underneath the wart. Smaller warts in close proximity were typically injected 
Table 1 Definition of responses

\begin{tabular}{|c|c|c|}
\hline & \multicolumn{2}{|l|}{ Responses } \\
\hline & Patient & Wart \\
\hline Complete response (CR) & $\begin{array}{l}100 \% \text { decrease of } \\
\text { cumulative wart area } \\
\text { (all warts had to clear) }\end{array}$ & $\begin{array}{l}100 \% \text { decrease in } \\
\text { individual wart area }\end{array}$ \\
\hline Partial response $(\mathrm{PR})$ & $\begin{array}{l}50 \text { to }<100 \% \text { decrease } \\
\text { of cumulative wart area }\end{array}$ & $\begin{array}{l}50 \text { to }<100 \% \text { decrease } \\
\text { of individual wart area }\end{array}$ \\
\hline None (NR) & $\begin{array}{l}<50 \% \text { decrease of } \\
\text { cumulative wart area }\end{array}$ & $\begin{array}{l}<50 \% \text { decrease of } \\
\text { individual wart area }\end{array}$ \\
\hline
\end{tabular}

by tracking the agent under the wart from a single puncture site. Larger warts were typically injected from multiple sites. The aim was to infiltrate the entire space with the study formulation and raise a weal encompassing the wart and surrounding adjacent tissue.

\section{EFFICACY AND SAFETY EVALUATIONS}

Efficacy was defined by wart measurements (length $x$ width) and number and quality of responses as outlined in table 1. Duration of response was defined as the time between complete response (CR) and observation of recurrence.

Safety was assessed by documenting immediate injection reactions, specific tissue conditions, and other adverse events and by means of laboratory studies. The tissue condition at the treatment site and the adjacent clinically uninvolved skin were evaluated for the presence and severity of any cutaneous reactions from an elicited list of possible tissue conditions, including erythema, swelling, desquamation, hyperpigmentation, erosion, ulceration, eschar, or necrosis. Brief physical examinations and laboratory evaluations were repeated after the last treatment as was the serum pregnancy test for female patients.

\section{STATISTICAL ANALYSES}

Study 1 (component contribution eight treatment group study)

The primary efficacy variables evaluated were patient response, time to complete response, recurrence, and time to recurrence. The contribution of 5-FU, adrenaline, and gel vehicle to patient response was analysed by three methods: analysis of covariance (ANCOVA)

Table 2 Study 1 and 2: characteristics of patient population

\begin{tabular}{|c|c|c|}
\hline Patient characteristics & Study 1 & Study 2 \\
\hline \multirow{17}{*}{$\begin{array}{l}\text { No treated } \\
\text { Sex } \\
\text { Male } \\
\text { Female } \\
\text { Mean age (year) (range) } \\
\text { Ethnic origin } \\
\text { White } \\
\text { Black } \\
\text { Hispanic } \\
\text { Other } \\
\text { Total no of warts treated } \\
\text { Site of warts } \\
\text { Penis } \\
\text { Vulvar } \\
\text { Other areas } \\
\text { No of warts per patient } \\
\text { median (range) } \\
\text { Median baseline total wart area (mm²) } \\
\text { (range) } \\
\text { Median disease duration (months) } \\
\text { (range) }\end{array}$} & 132 & 187 \\
\hline & 93 & 141 \\
\hline & & 46 \\
\hline & $33(17-61)$ & $35(18-82)$ \\
\hline & & \\
\hline & $102(77 \%)$ & $164(88 \%)$ \\
\hline & $18(14 \%)$ & $10(5 \%)$ \\
\hline & $9(7 \%)$ & $10(5 \%)$ \\
\hline & $3(2 \%)$ & $3(2 \%)$ \\
\hline & 686 & 858 \\
\hline & & \\
\hline & $\begin{array}{l}51 \% \\
21 \%\end{array}$ & $65 \%$ \\
\hline & $\begin{array}{l}21 \% \\
\leqslant 8 \%\end{array}$ & $\begin{array}{l}14 \% \\
\leqslant 6 \%\end{array}$ \\
\hline & & \\
\hline & $4(1-21)$ & $4(1-18)$ \\
\hline & $72 \cdot 5(2-450)$ & $56(1-532)$ \\
\hline & $24(3-288)$ & $24(1-444)$ \\
\hline
\end{tabular}

^Anal, perianal, groin, scrotal, perineal. on the percentage maximum decrease of total wart area from baseline; logistic regression on binary patient response ( $C R v$ not $C R$ ); and Cox regression on time to complete response. Response rates and cumulative recurrence rates were estimated by the Kaplan-Meier method.

\section{Study 2 (three treatment group study)}

Response rates per patient were calculated as the percentage of patients in a treatment group with complete response, partial response (PR), and non-response (NR) and were compared across treatment groups using the MantelHaenszel $\chi^{2}$ test with baseline total wart area as a covariate. Complete response rates were also estimated using the Kaplan-Meier methods. The Kaplan-Meier method was used to estimate time to complete recurrence rate and time to recurrence by treatment group.

\section{Results}

For both studies, efficacy was evaluated by per protocol analyses which included any patients who completed the clinical trial as designed per protocol or who dropped out early for a study related reason. Evaluation of safety was by intent to treat analyses which included any patients who were randomised into the study and received at least one dose of study drug.

\section{STUDY 1}

\section{Demographics}

A total of 146 patients were enrolled and treated and included in the safety analyses; 132 patients were evaluable for efficacy by per protocol analysis. Characteristics of the patient population are presented in table 2. Although the required minimum age was 18 , one 17 year old patient was enrolled with parental consent. Fourteen patients were excluded from efficacy evaluations for reasons that included non-compliance (eight), patient decision to discontinue (four), and pregnancy (two).

\section{Efficacy}

The complete and partial responses of all patients are summarised in figure 1 . In patients treated with formulations containing active agent, the per patient complete response rate was highest for the 5-FU/adrenaline gel group $(55 \%, 11 / 20)$, followed by the group treated with $5-\mathrm{FU} /$ adrenaline solution $(41 \%$, $9 / 22)$, then the $5-\mathrm{FU}$ gel group $(36 \%, 8 / 22)$, with the lowest complete response being for the $5-F U$ solution group $(13 \%, 3 / 24)$. Of the 11 patients in the 5-FU/adrenaline gel group who had complete responses, six (55\%) retained their complete response status and were free of recurrent warts at the 3 month follow up visit.

The highest complete response rate among groups treated with a formulation that did not contain active agent was in the adrenaline solution group $(17 \%, 2 / 12)$. Only one patient in the saline solution group $(10 \%, 1 / 10)$ and none of the patients in the adrenaline gel or placebo gel groups had a complete response. 


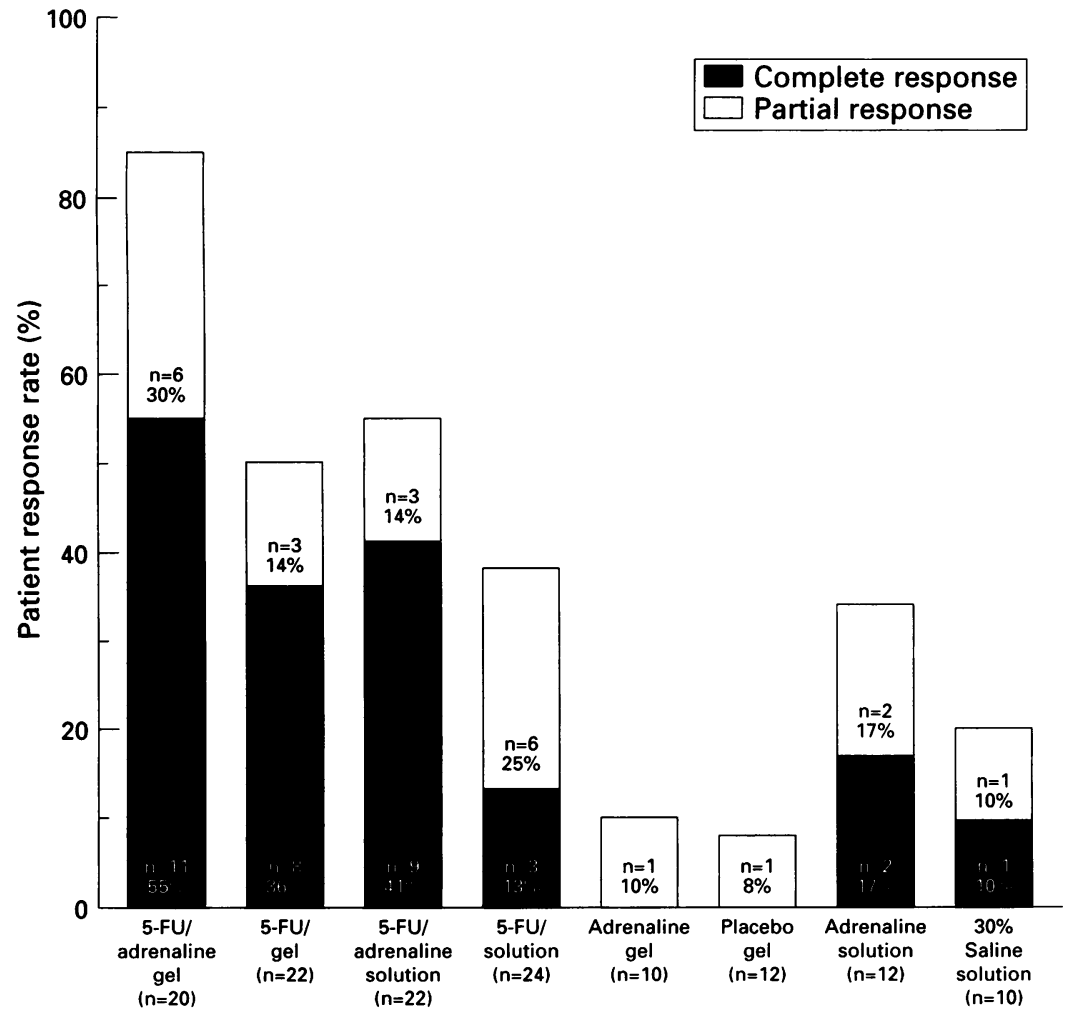

Figure 1 Study 1. Contribution of components of 5-FU/adrenaline injectable gel formulation to clinical efficacy.

\section{Safety}

No serious, unexpected, and clinically significant adverse events related to the test agents occurred during the study. Local cutaneous reactions at the treatment site were typically mild to moderate and resolved within 1 month after treatment. The frequency and severity of tissue conditions was greater in the patients treated with formulations containing fluorouracil. Transient pain at the injection site was the most common complaint, reported by nearly all $(98 \%)$ patients. No local anaesthetics were used in this study.

\section{STUDY 2}

\section{Demographics}

Eight clinical centres participated in this study, enrolling and treating 200 patients with a clinical diagnosis of external condylomata who were included in the safety analyses; 187 patients were evaluable for efficacy by per protocol analysis. Thirteen patients were excluded from efficacy evaluations because nine patients were non-compliant with protocol, three patients were lost to follow up, and one patient joined the military. The patient population characteristics are summarised in table 2 . The study treated all condylomata present at screening (one to 18 warts per patient, median of four warts per patient), resulting in a total of 858 evaluable condylomata. The baseline total wart area ranged from 1 to $532 \mathrm{~mm}^{2}$. Most patients $(59 \%)$ had received prior therapy for genital warts and were either treatment failures or had recurrent warts. The distributions of warts per patient and the baseline total treated wart area per patient are shown in figure 2. Sixty seven per cent of patients had five warts or fewer.

Baseline characteristics of the three treatment groups were comparable except that the individual baseline wart area was slightly higher in the placebo gel group than in the other two groups (medians: $9.0 \mathrm{~mm}^{2}$, for the 5-FU/adrenaline gel and 5-FU gel groups; $12.0 \mathrm{~mm}^{2}$, for the placebo gel group). A total of $132(71 \%)$ patients completed all six treatments. Some of the premature early terminations were because of an early complete response to treatment: $18 \%(14 / 78)$ for $5-F U /$ adrenaline gel and $11 \%(8 / 76)$ for $5-F U$ gel ( $0 \%$ for placebo).

\section{Efficacy}

For a patient to have a "complete response," all treated warts for that patient had to clear completely. Table 3 summarises the patient response rates by treatment group and by the three strata of initial wart area. Overall, complete response rate per patient was $65 \%$ in the 5-FU/adrenaline gel group (median four treatments), $54 \%$ in the 5 -FU gel group (median five treatments), and $15 \%$ in the placebo gel group. Comparing patients who had a complete response with those who did not (that is, $\mathrm{CR} v \mathrm{PR}+\mathrm{NR}$ ) indicates that patients treated with 5-FU/adrenaline gel had a significantly higher $C R$ rate $(p=0.039)$ than those treated with 5-FU gel without adrenaline. In both the 5-FU adrenaline/gel and 5-FU gel groups,

\begin{abstract}
on the change in total wart area conditional of 5 -FU was statistically significant $(p=$ $0.009)$.

In summary, as independent components, 5-FU and adrenaline directly affect complete response and time to complete response, and the collagen gel vehicle (with 5-FU) significantly improves complete response rates. Al three components strongly influence the decrease in total wart area produced by treatment.
\end{abstract}


A

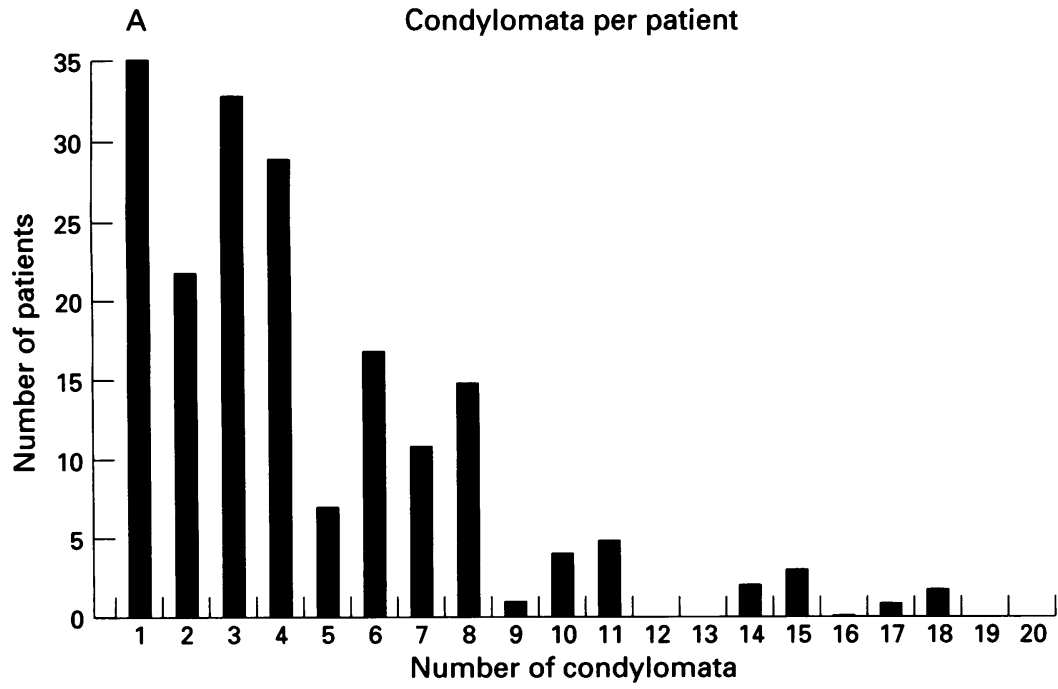

B Pretreatment total condyloma area per patient

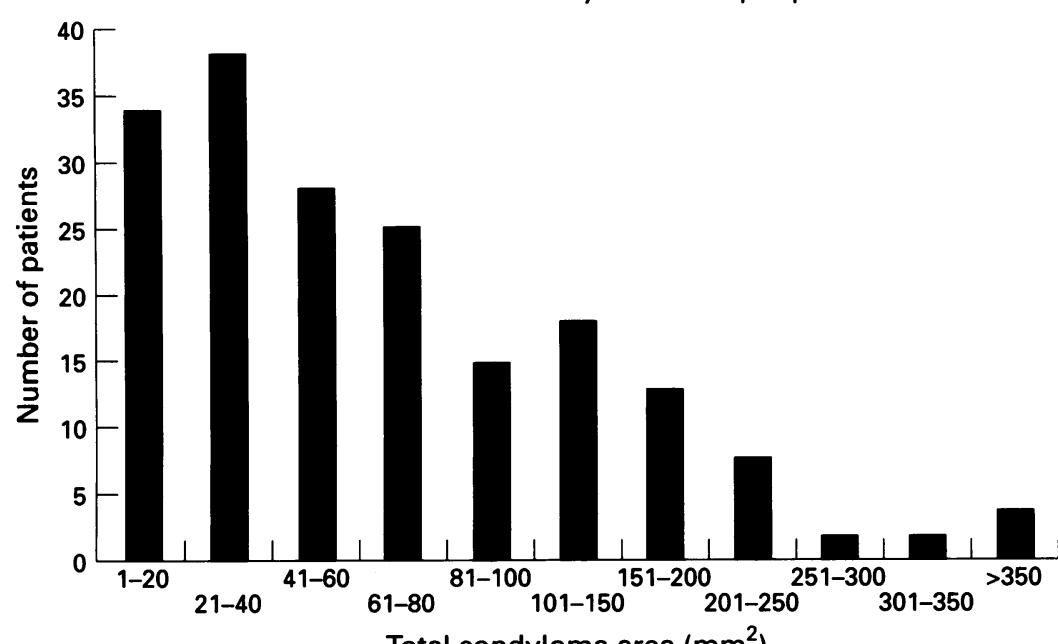

Total condyloma area $\left(\mathrm{mm}^{2}\right)$

Figure 2 Study 2. Baseline disease characteristics for patients. (A) In a total of 187 patients with 858 condylomata from one to 18 warts per patient (median 4) were treated. (B) Baseline total wart area per patient ranged from 1 to $532 \mathrm{~mm}^{2}$ (median $55 \mathrm{~mm}^{2}$ ).

overall per patient response rates were superior $(p \leqslant 0.01)$ to placebo gel alone. The combined complete and partial response rate was $78 \%$ for those receiving 5 -FU/adrenaline gel and $76 \%$ for those receiving $5-\mathrm{FU}$ gel ( $\mathrm{p}$

Table 3 Study 2: patient response to treatment by total pretreatment wart area and treatment group

\begin{tabular}{llcc}
\hline \multirow{2}{*}{$\begin{array}{l}\text { Total pretreatment } \\
\text { wart area }\end{array}$} & \multicolumn{2}{l}{ Response (No of patients (\%)) } \\
\cline { 2 - 4 } & $5-$ FUladrenaline gel & $5-F U$ gel & Placebo gel \\
\hline $55 \mathrm{~mm}^{2}$ & & & \\
Complete & $34(87)$ & $29(69)$ & $2(17)$ \\
Partial & $2(5)$ & $4(10)$ & $0(0)$ \\
None & $3(8)$ & $9(21)$ & $10(83)$ \\
Total & 39 & 42 & 12 \\
$56-100 \mathrm{~mm}^{2}$ & $11(61)$ & $9(47)$ & $1(10)$ \\
Complete & $4(22)$ & $6(32)$ & $0(0)$ \\
Partial & $3(17)$ & $4(21)$ & $9(90)$ \\
None & 18 & 19 & 10 \\
Total & $6(29)$ & $3(20)$ & $2(18)$ \\
100 mm & $4(19)$ & $7(47)$ & $0(0)$ \\
Complete & $11(52)$ & $5(33)$ & $9(82)$ \\
Partial & 21 & 15 & 11 \\
None & $51(65)$ & $41(54)$ & $5(15)$ \\
Total & $10(13)$ & $17(22)$ & $0(0)$ \\
Overall & $17(22)$ & $18(24)$ & $28(85)$ \\
Complete & 78 & 76 & 33 \\
Partial & & & \\
None & & & \\
Total & & & \\
\hline
\end{tabular}

$<0.001$ for both active formulations when compared with placebo gel).

Baseline total wart area appeared to influence response rates: patients with lower total baseline wart areas, reflecting fewer numbers of warts or smaller warts, had the highest rates of complete response. For example, for patients treated with 5-FU adrenaline/gel, those with a total wart area $\leqslant 55 \mathrm{~mm}^{2}$ had an $87 \%$ CR rate, those with a total wart area of $56-100 \mathrm{~mm}^{2}$ had a $61 \% \mathrm{CR}$ rate, whereas those with a total wart area $>100 \mathrm{~mm}^{2}$ had a $29 \%$ CR rate. In this study population sample, nearly twice as many patients had a total wart area $\leqslant 55 \mathrm{~mm}^{2}$ as those who had total wart areas of either $56-100 \mathrm{~mm}^{2}$ or $>100 \mathrm{~mm}^{2}$.

Similarly, in terms of individual condyloma responses, small warts responded better than large ones, as shown in table 4 . The CR rate for individual warts $<4 \mathrm{~mm}^{2}$ treated with 5-FU adrenaline/gel (86\%) was $14 \%$ higher than for warts in the 4-12 $\mathrm{mm}^{2}$ range, and complete response rate for warts $4-12 \mathrm{~mm}^{2}$ was $13 \%$ higher than for warts $>12 \mathrm{~mm}^{2}$. Included in the size group $>12 \mathrm{~mm}^{2}$ were warts of up to $200 \mathrm{~mm}^{2}$.

Erosion and ulceration were positively associated with complete response and may be part of the response process of wart elimination. In the 5-FU/adrenaline gel group, patients with erosion or ulceration had a higher response rate than patients without these cutaneous reactions, and this difference was statistically significant.

Time to complete patient response depended on the investigational agent used. Patients treated with 5-FU/adrenaline gel responded in a shorter time (median time to a patient CR of 48 days) than patients treated with 5-FU gel (median time to $C R$ of 65 days). This difference was significantly shorter ( $p=0.0098$ ). Furthermore, the time to achieve a complete response was significantly shorter in patients with smaller total wart areas: patients with baseline wart areas $\leqslant 55 \mathrm{~mm}^{2}$ treated with 5-FU/adrenaline gel cleared in a median of 40 days compared with 46 days for those treated with $5-\mathrm{FU}$ gel ( $\mathrm{p}=$ 0.03).

Recurrence was evaluated in two ways. Patients with complete responses were evaluated at 3 months after response for wart recurrence, and the recurrence of one or more treated warts was defined as a "patient recurrence". No statistically significant differences between the two active treatment groups were found. Ninety day cumulative recurrence rates following complete response were $43 \%$ in the 5-FU/adrenaline gel group and $50 \%$ for the 5-FU gel group. We also evaluated recurrences of individual warts ("wart recurrence"). Cumulative 90 day recurrence rates were lower for the 5-FU/adrenaline gel group (31\%) compared with the 5-FU gel group $(47 \%)$.

\section{Safety}

Most patients tolerated the treatments well. The majority $(97-100 \%)$ of patients experienced mild to moderate burning, stinging, or 
Table 4 Study 2: individual wart response rates by pretreatment wart area and treatment group

\begin{tabular}{|c|c|c|c|}
\hline \multirow{2}{*}{$\begin{array}{l}\text { Individual pretreatment } \\
\text { wart area }\end{array}$} & \multicolumn{3}{|c|}{ Response (No of patients (\%)) } \\
\hline & 5-FUladrenaline gel & $5-F U$ gel & Placebo gel \\
\hline \multicolumn{4}{|l|}{$<4 \mathrm{~mm}^{2}$} \\
\hline Complete & $42(86)$ & $35(51)$ & $6(50)$ \\
\hline Partial & $0(0)$ & $2(3)$ & $0(0)$ \\
\hline None & $7(14)$ & $32(46)$ & $6(50)$ \\
\hline Total & & & \\
\hline \multicolumn{4}{|l|}{$4-12 \mathrm{~mm}^{2}$} \\
\hline Complete & $127(72)$ & $95(68)$ & $13(19)$ \\
\hline Partial & $17(10)$ & $11(8)$ & $8(12)$ \\
\hline None & $33(19)$ & $34(24)$ & $48(70)$ \\
\hline $\begin{array}{l}\text { Total } \\
>12 \mathrm{~mm}^{2} \text { (up to } 200 \mathrm{~mm}^{2} \text { ) }\end{array}$ & 177 & 140 & $>12 \mathrm{~mm}^{2}$ (up to $200 \mathrm{~mm}^{2}$ ) \\
\hline Complete & 77 (59) & $85(60)$ & $12(17)$ \\
\hline Partial & $14(11)$ & $22(15)$ & $5(7)$ \\
\hline None & $39(30)$ & $35(25)$ & $53(76)$ \\
\hline Total & 130 & 142 & 70 \\
\hline \multicolumn{4}{|l|}{ Overall } \\
\hline Complete & $246(69)$ & $215(61)$ & $31(21)$ \\
\hline Partial & $31(9)$ & $35(10)$ & $13(9)$ \\
\hline None & $79(22)$ & $101(29)$ & $107(71)$ \\
\hline Total & 356 & 351 & 151 \\
\hline
\end{tabular}

transient pain (lasting 15 to 20 minutes) after injection of any test agent. While no local anaesthetics were permitted in the study protocol, we expect that in the general clinical use of the product topical or injected anaesthetics could be used to lessen the transient injection discomfort. Mild to moderate tissue reactions were common in the 5-FU/adrenaline gel and 5-FU gel groups and typically resolved by the end of the follow up period. Tissue reactions were limited to the treated site and included erythema (94\%, 88\%), swelling/induration (98\%, 65\%), desquamation $(72 \%, 63 \%)$, eschar $(76 \%, 55 \%)$, and hyperpigmentation $(67 \%, 64 \%)$ for the two drug treatment groups, respectively. Erosion $(90 \%)$ and ulceration (63\%) were more common in patients treated with 5-FU/adrenaline gel, reached a peak after either the third or fourth injection, and usually resolved without complications by the 90 day follow up visit. As stated before, erosion and ulceration were positively associated with complete response to treatment and appear to be part of the response process.

Adverse events other than injection site pain and local cutaneous reactions were rare. Three treatment related, serious adverse events were reported in patients treated with 5-FU gel. These were localised to the treatment site and represented exacerbations of the commonly observed tissue reaction. One patient had progressive ulceration on the penis shaft that was treated surgically with no sequelae. Another patient reported severe pain at the injection site, moderate induration, and swelling; the remaining patient had a persistent nodule probably related to residual collagen.

Of 86 patients with ulceration who were followed to resolution, seven patients were reported to have a scar, all of which were located on the penis. Five of these patients had been treated with 5-FU/adrenaline gel and two patients with 5-FU gel. Although investigators classified ulceration as any tissue condition they believed was likely to result in scarring, even in the absence of a scar, no reclassifications were made. No scars were reported as adverse events in this study.

\section{Discussion}

The 5-FU/adrenaline injectable gel provides a new therapeutic approach to treatment of condylomata acuminata. Administration by intradermal injection provides targeted delivery of active drugs to the diseased tissue. The viscous gel protein carrier matrix significantly enhances the retention of the drugs and maintains high local drug concentrations for longer periods than is possible for fluorouracil administered as a simple aqueous solution. After release of the drugs, the biodegradable protein matrix is resorbed. The sustained release intralesional delivery formulation increases the therapeutic index by increasing drug exposure in the wart area. This has been documented by $\stackrel{\varnothing}{\varnothing}$ drug retention ${ }^{9}$ and drug distribution studies ${ }^{15}$ क in preclinical mouse tumour model systems.

In study 1 , our goal was to assess the component contribution of 5-FU, adrenaline, and $\vec{\omega}$ the collagen gel vehicle to treatment. Each component had a statistically significant effect on reduction of total baseline wart area. 5-FU and adrenaline had a significant effect on complete response rate, whereas the combination $\cong$ of 5-FU and the collagen gel vehicle $\frac{}{2}$ approached significance. The combination of all three components resulted in the highest complete response rate compared with any individual component or combination. Thus, the 5-FU/adrenaline gel delivery system does indeed improve the therapeutic outcome and provides a synergistic effect.

Study 2, with a larger number of patients divided among fewer treatment groups, was designed to assess in greater depth the effect of adrenaline on treatment, as well as to assess the effectiveness and safety of 5-FU/adrenaline gel, 5-FU gel (without adrenaline), and $\overline{0}$ placebo gel. Both 5-FU/adrenaline gel and 5-FU gel had significantly greater effects on overall patient complete response than placebo gel. Furthermore, 5-FU/adrenaline gel was significantly more effective than 5-FU gel. The effect of adrenaline was more evident temporally; however, patients treated with 5-FU/ adrenaline gel achieved complete responses in significantly shorter time than did patients treated with 5-FU gel.

The therapeutic response to treatment with 5-FU/adrenaline gel was related to the extent of the patients' disease. Patients with the $N$ smallest total wart areas had the highest $\underset{\omega}{N}$ response rates. In the population sample in study 2 the median total wart area was of $55 \mathrm{~mm}^{2}$. Patients with total wart areas of less $\mathbb{D}$ than $55 \mathrm{~mm}^{2}$ had a complete response rate of $87 \%$, which suggests that $5-\mathrm{FU} /$ adrenaline gel $\frac{0}{0}$ is a highly effective treatment modality. With increasing wart area, the complete response $\mathbb{D}$ rates decreased, although many patients had $\frac{\Omega}{\sigma}$ notable reductions in total wart burden. This pattern of response has been substantiated in a $\frac{\delta}{0}$ larger trial. ${ }^{16}$ In a separate small study, a second cycle of a few additional treatments with 5-FU/adrenaline gel improved response rates, especially in patients with numerous warts, large total wart areas $\left(\geqslant 100 \mathrm{~mm}^{2}\right)$, or those with partial responses. ${ }^{17}$

Treatments with 5-FU/adrenaline gel were 
well tolerated. The reported local cutaneous reactions, such as erythema, desquamation, erosion, ulceration, and hyperpigmentation, were anticipated and confined to the treatment site. Patients with erosions and ulceration experienced higher response rates than those that did not, and these cutaneous reactions appear to be part of the response process. External condylomata in all anatomic sites were safely and effectively treated. While there is a perception that adrenaline should be used with caution on the penis, no local serious adverse effects attributable to the vasoconstrictive properties of adrenaline were noted in the penile condylomata treated with 5-FU/adrenaline injectable gel.

In summary, in these clinical studies 5-FU/ adrenaline injectable gel was found to be more efficacious in the treatment of condylomata acuminata than any of its formulation components. Study 1 demonstrated that the combination of 5-FU, adrenaline, and the collagen gel vehicle had a synergistic effect on therapeutic outcome. Study 2 showed that the highest complete response rates were in the 5-FU/adrenaline gel group and that inclusion of adrenaline in this formulation significantly reduced the time to a complete response. In both studies, the treatments with 5-FU/ adrenaline gel were safe and well tolerated. The benefits of intralesional therapy noted throughout these studies include high response rates, low recurrence rates, simplicity of outpatient treatment, and lack of clinically significant systemic adverse reactions related to treatment. Additional clinical trials are warranted to further evaluate the safety and efficacy of multiple treatment courses for patients with recurrent or new genital warts, and as well in immunosuppressed patients such as those who have had a renal transplant or are positive for human immunodeficiency virus. The 5-FU/adrenaline injectable gel may serve as an appropriate treatment option for male and female patients with condylomata acuminata.

We acknowledge the contribution of the following investigator who also participated in the study: $\operatorname{Dr} L$ Eron (Annandale, VA), Dr S Kraus (Atlanta, GA), Dr S Thein (San Diego, CA) Dr L Parish (Philadelphia, PA), Dr J Shrum (New Orleans, LA), Dr K Beutner (Vallejo, CA), Dr C Cockerell (Dallas,
TX), Dr W Lang (San Francisco, CA), and Dr R Reichman (Rochester, NY). Dr M Stewart, C Zhao, and S Wong provided statistical analysis, and C Rickhoff and Dr J Windt provided editorial assistance.

This clinical study was supported by a grant from Matrix Pharmaceutical, Inc, Fremont, California, USA.

1 Division of STD Prevention. Atlanta: US Department of Health and Human Services, Public Health Services, Centers for Disease Control and Prevention, 1995.

2 Stone $K$. Human papillomavirus infection and genital warts: update on epidemiology and treatment. Clin Infect warts: update on epidemiology
Dis 1995;20(suppl 1):S91-7.

3 Ling MR. Therapy of genital human papillomavirus infections. Part I: Indications for and justification of therapy. Int $\mathcal{F}$ Dermatol 1992;31:682-6.

4 Dretler S, Klein L. The eradication of intraurethral condyloma acuminata with 5 percent 5 -fluorouracil cream. $f$ Urol 1975;113:195-8.

5 von Krogh G. 5-Fluorouracil cream in the successful treatment of therapeutically refractory condylomata of the urinary meatus. Acta Derm Venereol (Stockh) 1976;56: 297-301.

6 Ferenczy A. Comparison of 5-fluorouracil and $\mathrm{CO}_{2}$ taser for treatment of vaginal condylomata. Obstet Gynecol $1984 ; 64: 773-8$

$7 \mathrm{Krebs} \mathrm{HB}$. The use of topical 5-fluorouracil in the treatment of genital condylomas. Obstet Gynecol Clin N Am 1987;14:559-68.

8 Maymon R, Shulman A, Maymon BB, Bekerman A, Werchow M, Faktor JH, et al. Penile condylomata: a gynecological epidemic disease: a review of the current approach and management aspects. Obstet Gynecol Surv 1994;49:790-800

9 Yu NY, Orenberg EK, Luck EE, Brown DM. Antitumor effect of intratumoral administration of fluorouracil/epinephrine injectable gel in $\mathrm{C} 3 \mathrm{H}$ mice. Cancer Chemother Pharmacol 1995;36:27-34.

10 Orenberg EK, Miller BH, Greenway HT, Koperski JA, Lowe N, Rosen T, et al. The effect of intralesional 5-fluorouracil therapeutic implant (MPI 5003) for treatment of basal cell carcinoma. $\mathcal{F}$ Am Acad Dermatol 1992;27: basal cell

11 Miller BH, Shavin JS, Cognetta A, Taylor RJ, Salasche S, Korey A, et al. Nonsurgical treatment approach for basal cell carcinoma with intralesional fluorouracil/epinephrine injectable gel. $\mathcal{A}$ Am Acad Dermatol 1997;36:72-7.

12 Kitchell BE, Orenberg EK, Brown DM, Hutson C, Ray K, Woods $\mathrm{L}$, et al. Intralesional sustained-release chemotherapy with therapeutic implants for treatment of canine sun-induced squamous cell carcinoma. Eur $\mathcal{F}$ Cancer 1995;31A:2093-8.

13 Miller BH, Georgouras K, Griffin E, Korey A, Kraus S, Orenberg EK, et al. A nonsurgical treatment of squamous Orenberg EK, et al. A nonsurgical treatment of squamous rouracil/epinephrine) Injectable Gel. [abstract no 166] rouracil/epinephrine) Injectable Gel. [abstract no 166]. In: Program and abstracts of Clinical Dermatology

14 Lowe NJ, Nychay S, Orenberg EK, Korey A. Intradermal fluorouracil and epinephrine injectable gel for treatment of psoriatic plaques. Arch Dermatol 1995;131:1340-1.

15 Sahai A, Kanekal S, Jones RE, Brown D. An injectable sustained-release drug delivery system markedly enhances intratumoral retention of ${ }^{14} \mathrm{C}$-fluorouracil in murine fibrosarcomas. [abstract no 1843]. In: Proceedings of the 86th Annual 86th Annual Meeting of the American Association for

16 Cancer Research. Toronto, Ontario, 18-22 March 1995. McCarty JM, et al. Intralesional fluorouracil/epinephrine McCarty JM, et al. Intralesional fluorouracil/epinephrine injectable gel for treatment of

17 Swinehart JM, Korey A, Orenberg EK. Relationship of genital wart burden to therapeutic response to fluorouracil/epinephrine injectable gel. Int $\mathcal{f}$ STD $\mathcal{E}$ AIDS 1997;8:A1098.1-4 